\title{
Labeled-peptides-free UHPLC-MS/MS Method Used for Simultaneous Determination of Shrimp and Soybean in Sauce Products
}

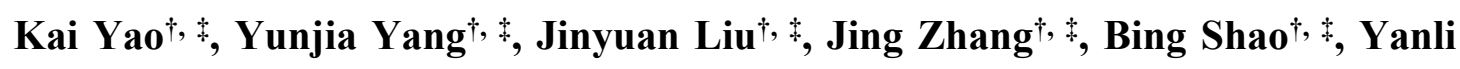
Zhang ${ }^{\S}$ *

$\uparrow$ Beijing Key Laboratory of Diagnostic and Traceability Technologies for Food Poisoning, Beijing Center for Disease Prevention and Control, Beijing 100013, People's Republic of China

¥ Beijing Research Center for Preventive Medicine, Beijing 100020, People’s Republic of China

$\S$ Department of Gastroenterology, China-Japan Friendship Hospital, Beijing 100029, China

*Corresponding author: janetzyl@aliyun.com 


\section{Figure captions:}

Figure S1. Extracting solutions optimization of each peptide for (A) tropomyosin and (B) Gly $\mathrm{m} 6$ in contaminated sauce (100 $\mu \mathrm{g}$ protein/g). Figure S2. Extraction modes optimization of each peptide for (A) tropomyosin and (B) Gly $\mathrm{m} 6$ in contaminated sauce (100 $\mu \mathrm{g}$ protein $/ \mathrm{g}$ ).

Figure S3. Dosage of enzyme optimization of each peptide for (A) tropomyosin and (B) Gly $\mathrm{m} 6$ in contaminated sauce (100 $\mu \mathrm{g}$ protein $/ \mathrm{g})$.

Figure S4. Digestion time optimization of each peptide for (A) tropomyosin and (B) Gly $\mathrm{m} 6$ in contaminated sauce (100 $\mu \mathrm{g}$ protein $/ \mathrm{g})$. 


\section{Figure S1.}

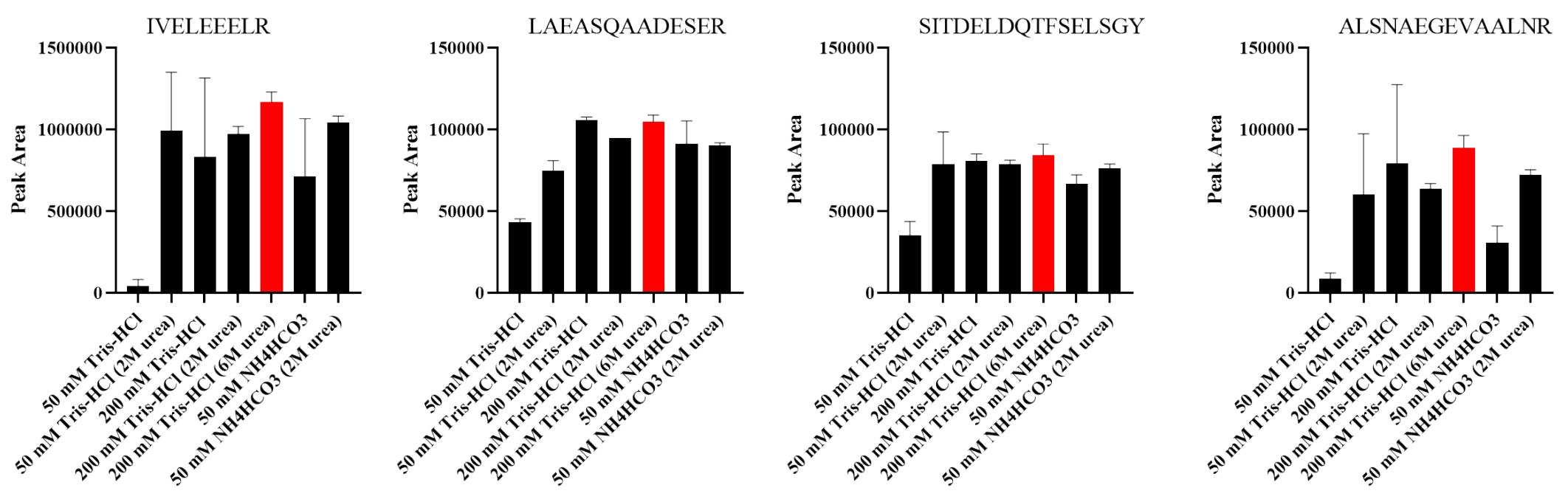

(A) 

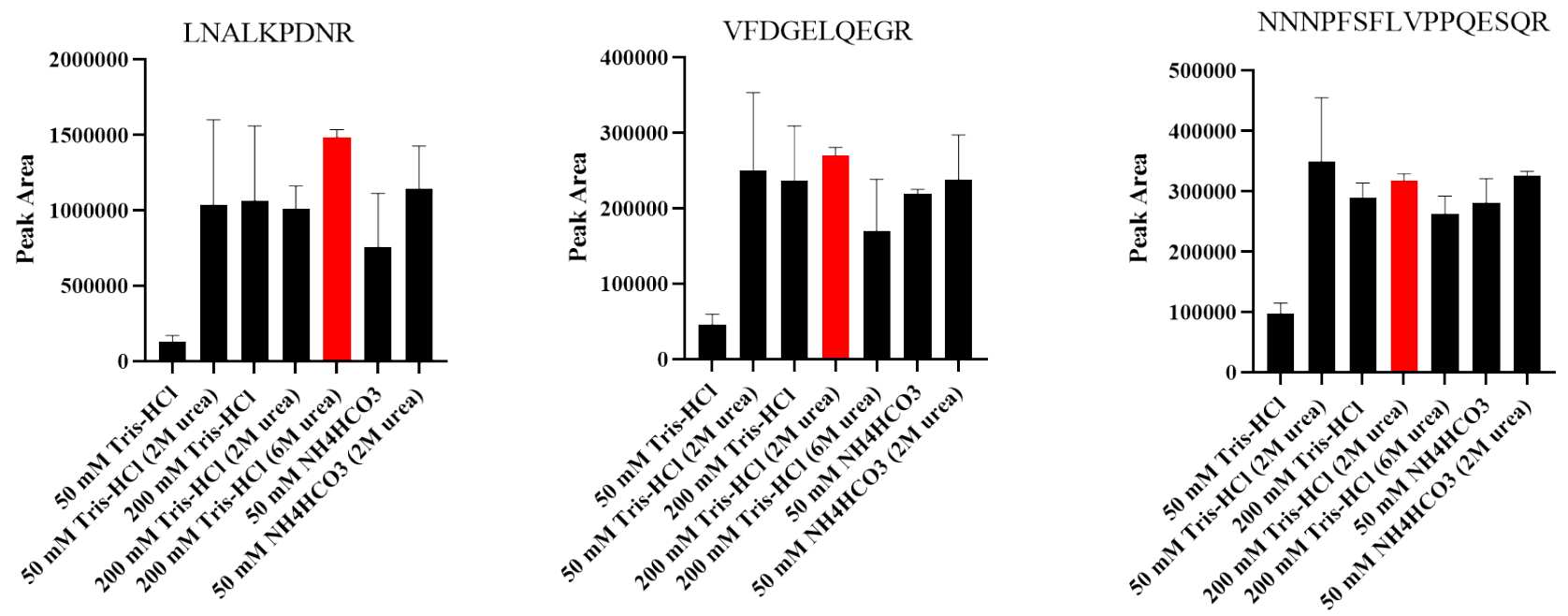

FYLAGNQEQEFLK

SQSDNFEYVSFK
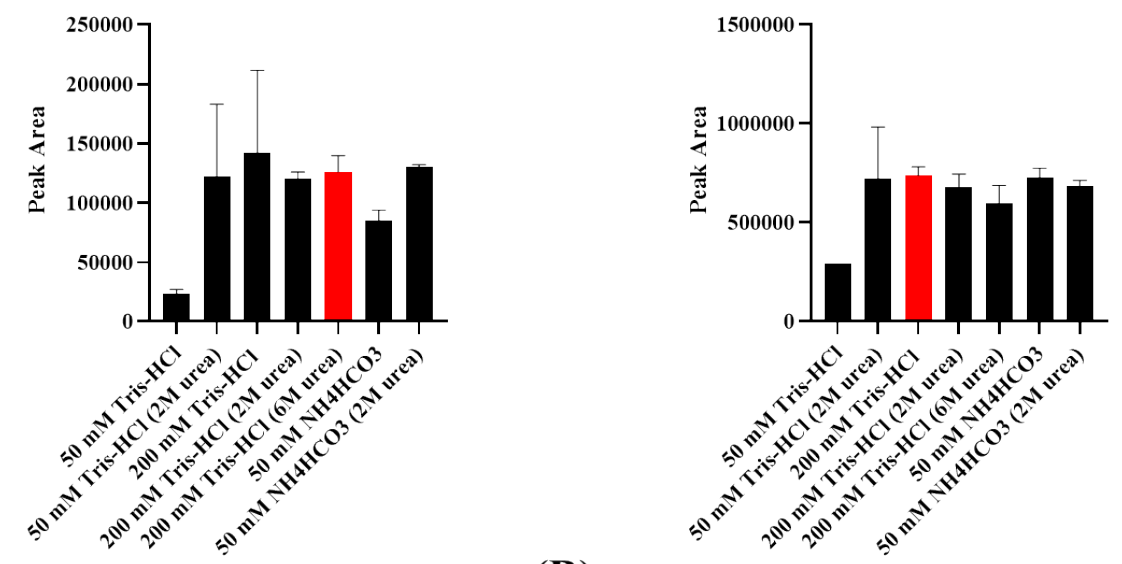

(B) 
Figure S2.

IVELEEELR

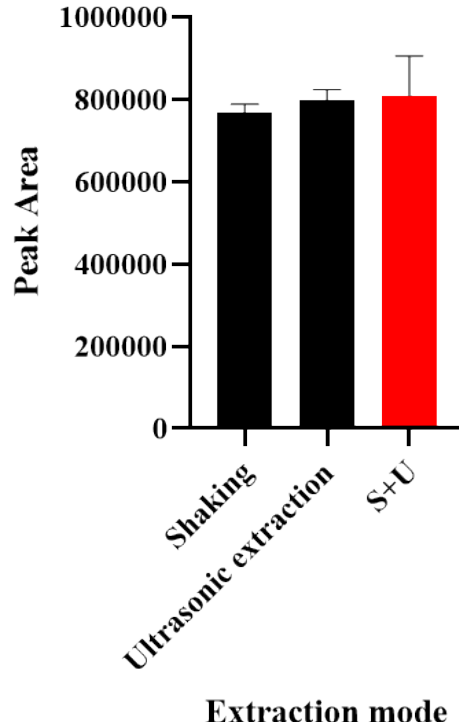

LAEASQAADESER

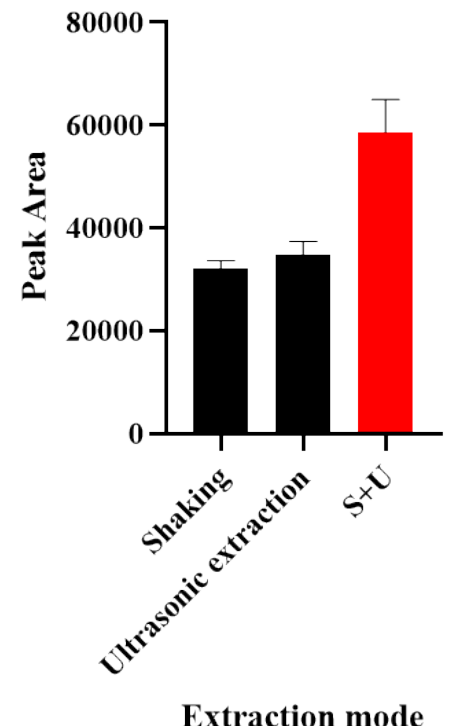

SITDELDQTFSELSGY

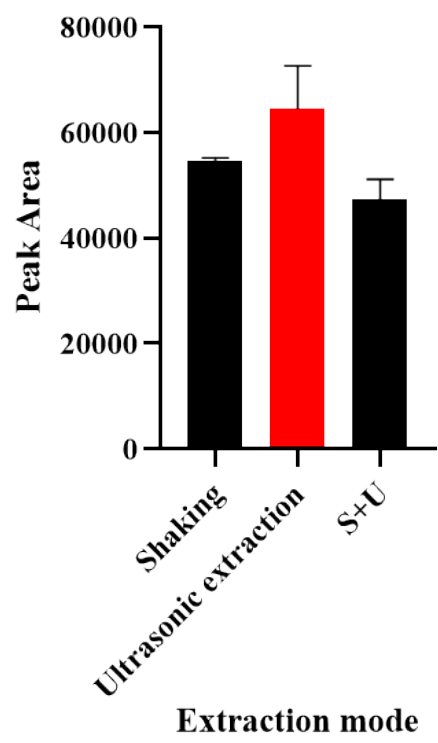

ALSNAEGEVAALNR

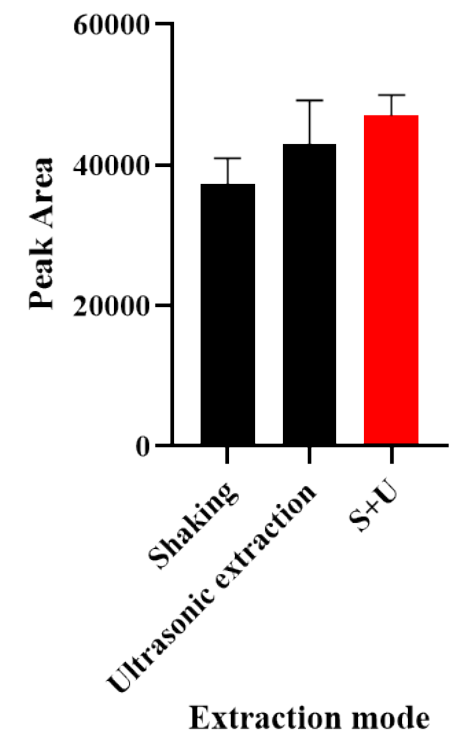

(A) 

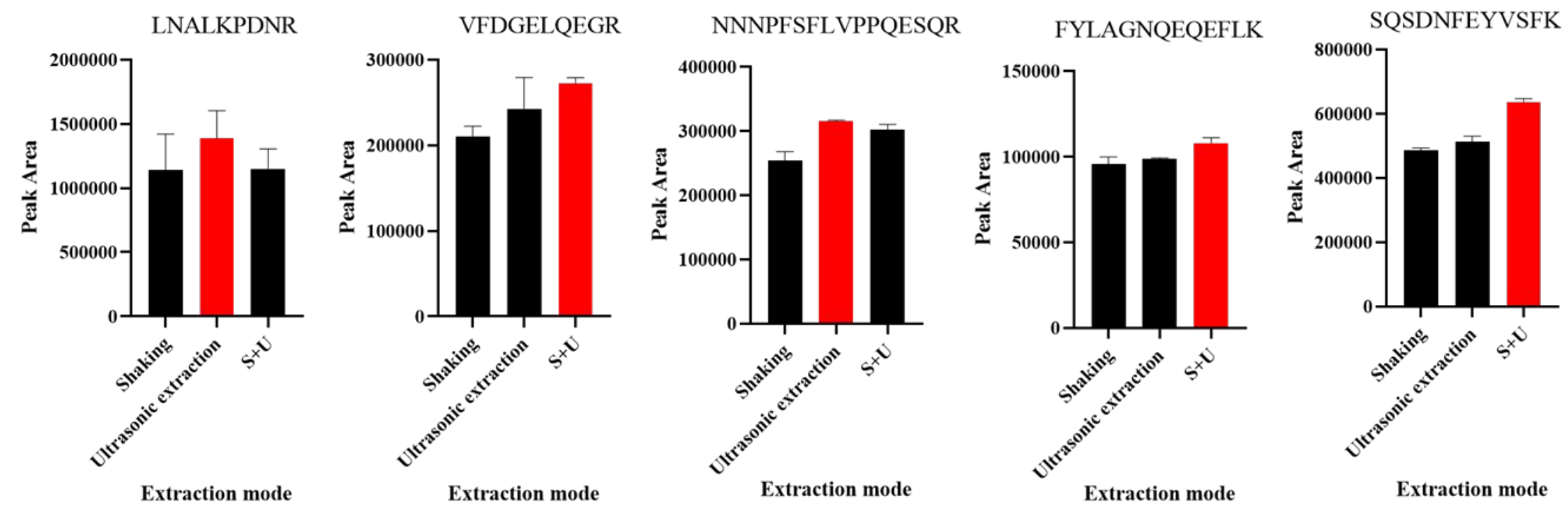

(B) 
Figure S3.
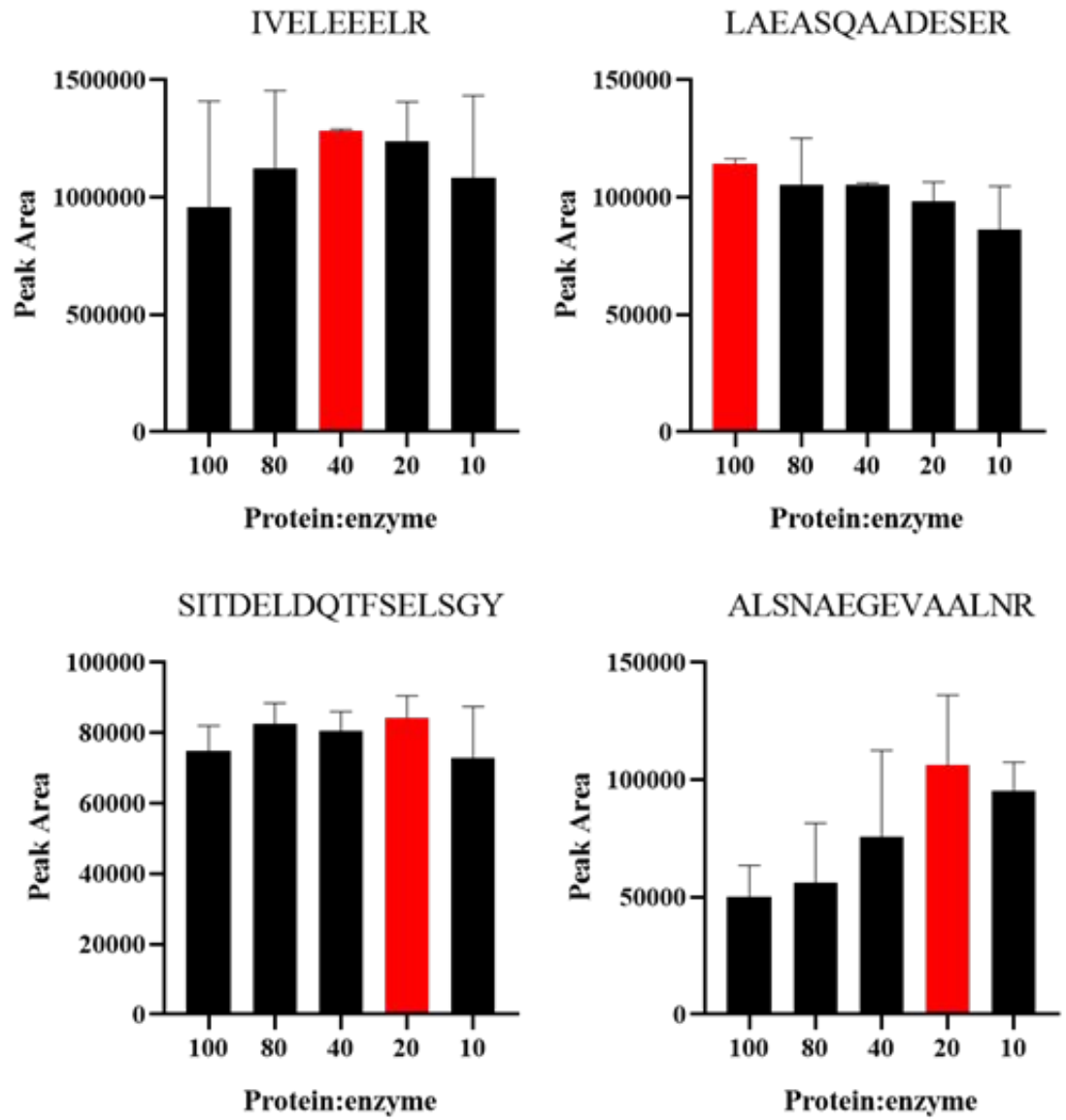

(A) 
LNALKPDNR

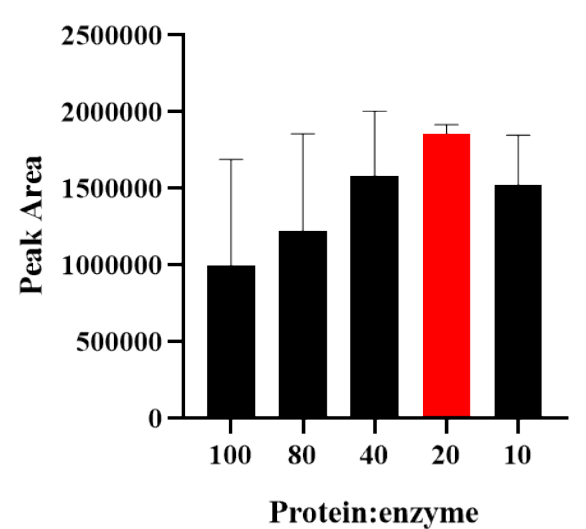

VFDGELQEGR

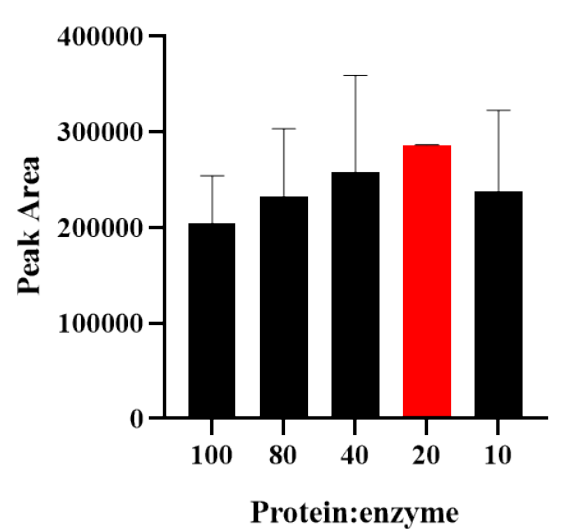

NNNPFSFLVPPQESQR

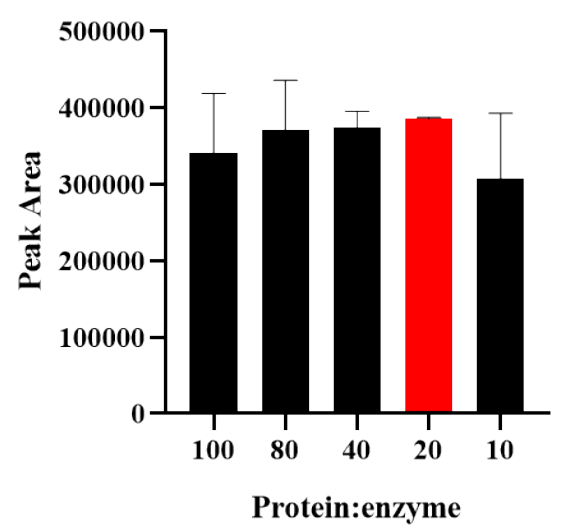

FYLAGNQEQEFLK

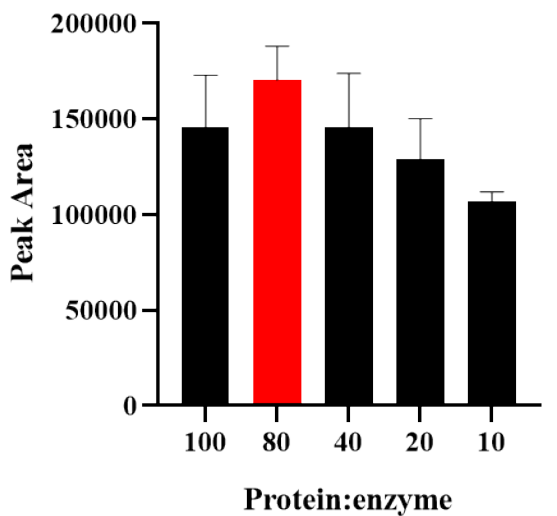

SQSDNFEYVSFK

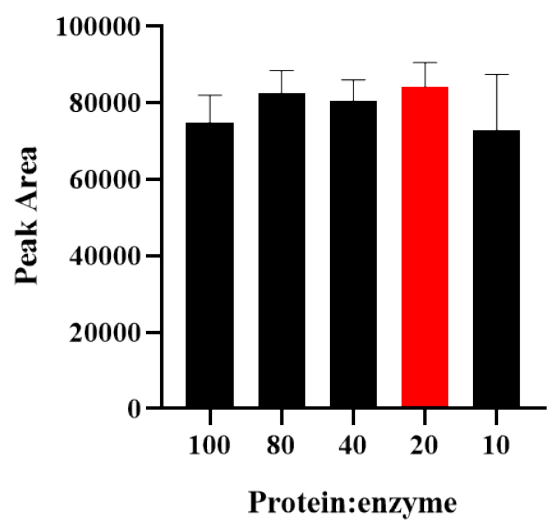

(B) 
Figure S4
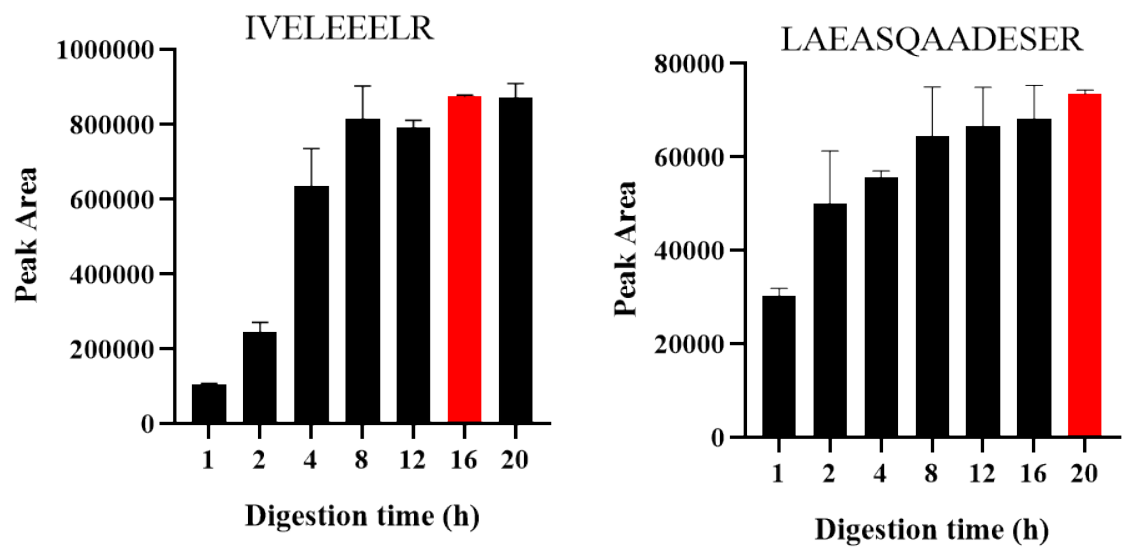

SITDELDQTFSELSGY
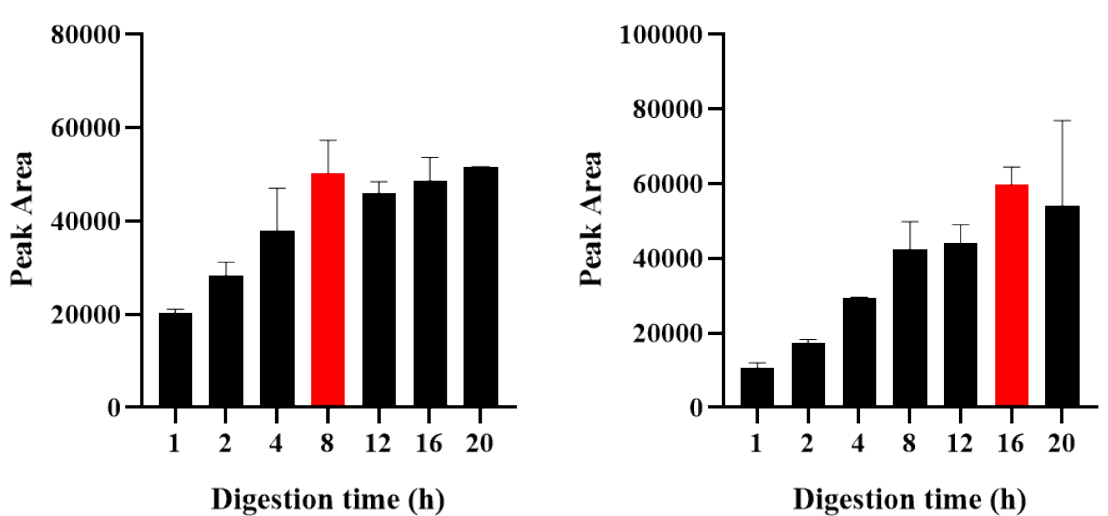

(A) 

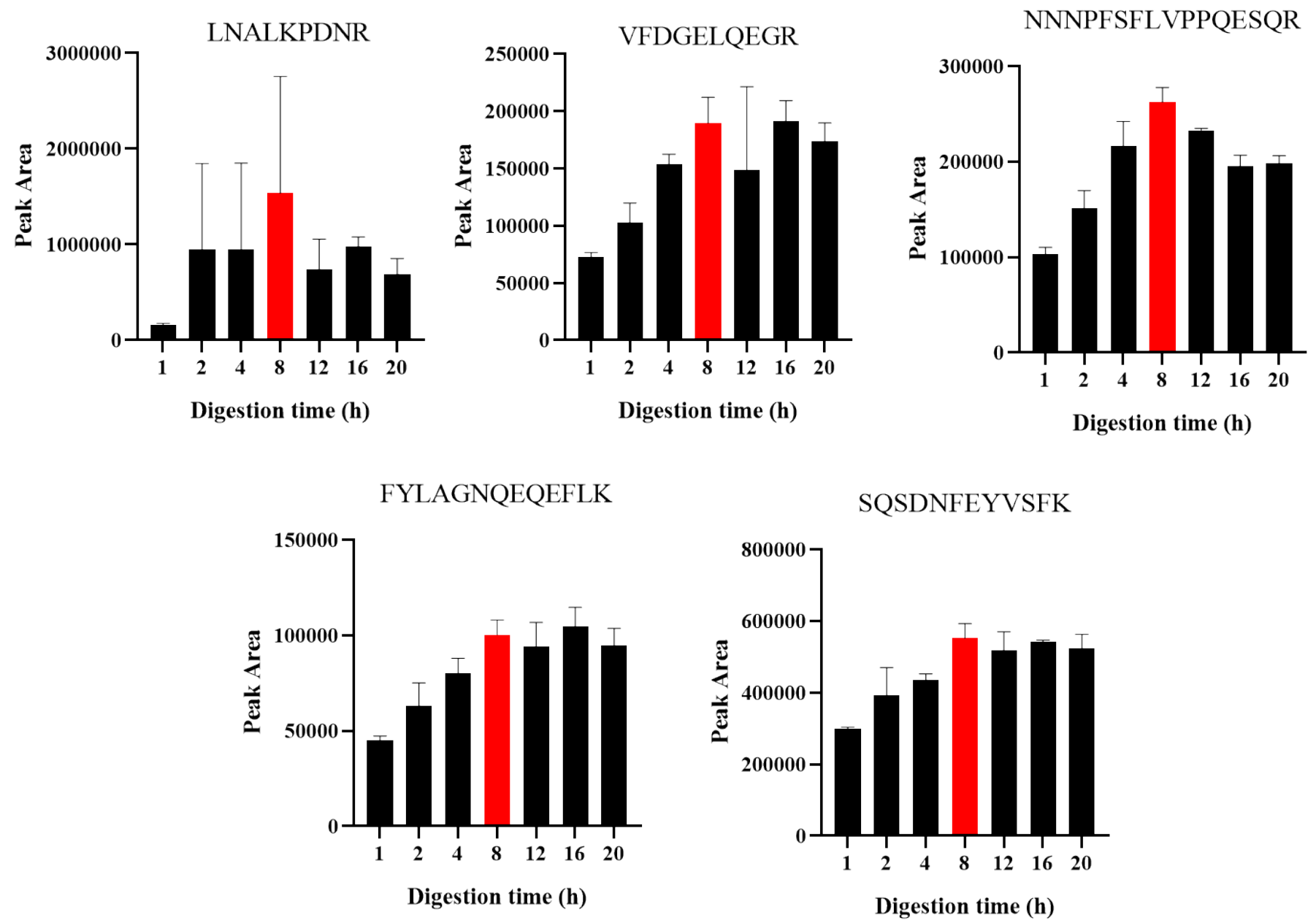

(B) 